\title{
Risk Factors Associated with Prolonged Postoperative Opioids Use in Non-Cancer Patients Undergoing Spinal Surgery: A Retrospective Study
}

\author{
Arpawan Thepsuwan, M.D.', Sasikaan Nimmaanrat, M.D.', Paramee Thongsuksai, M.D. ${ }^{2}$ \\ ${ }^{1}$ Department of Anesthesiology, Faculty of Medicine, Prince of Songkla University, Hat Yai, Songkhla 90110, Thailand. \\ 2Department of Biomedical Sciences, Faculty of Medicine, Prince of Songkla University, Hat Yai, Songkhla 90110, Thailand. \\ Received 9 November 2021 • Revised 20 January 2022 • Accepted 20 January 2022 • Published online 3 March 2022
}

\begin{abstract}
:
Objective: To identify risk factors associated with prolonged postoperative opioids use in non-cancer patients undergoing spinal surgery.

Material and Methods: The medical records of patients, who underwent spinal surgery at Songklanagarind Hospital; from January 2014 to January 2019, were retrospectively reviewed, Data analysis was performed using multinomial logistic regression to identify independent factors associated with prolonged postoperative opioids use.

Results: There were 65 out of 500 patients (13.0\%) who had prolonged postoperative opioids usage. Opioids used before surgery as well as length of hospital stay after surgery were risk factors associated with prolonged postoperative opioids use (relative risk (RR), 47.65; 95\% Cl, 17.67-128.49 and RR, 1.07; 95\% Cl, 1.01-1.14, respectively). Whereas, preoperative gabapentinoids use reduced the risk of prolonged postoperative opioids use ( $\mathrm{RR}, 0.33$; 95\% $\mathrm{Cl}, 0.13-0.83)$.

Conclusion: Avoiding preoperative opioids used, by using gabapentinoids instead could reduce the risk associated with prolonged postoperative opioids use; in addition to related morbidity and mortality in non-cancer spinal pain patients.
\end{abstract}

Keywords: non-cancer patients, postoperative opioid, prolonged opioids use, risk factors, spinal surgery

Contact: Arpawan Thepsuwan, M.D.

Department of Anesthesiology, Faculty of Medicine, Prince of Songkla University, Hat Yai, Songkhla 90110, Thailand.

E-mail: arpawanthepsuwan@gmail.com

(c) 2022 JHSMR. Hosting by Prince of Songkla University. All rights reserved.

This is an open access article under the CC BY-NC-ND license

(http://www.jhsmr.org/index.php/jhsmr/about/editorialPolicies\#openAccessPolicy).
J Health Sci Med Res 2022;40(5):571-584 doi: 10.31584/jhsmr.2022869 www.jhsmr.org 


\section{Introduction}

According to the International Association for the Study of Pain (IASP) and the World Health Organization (WHO) analgesic ladder, opioids are recommended for short-term management of acute postoperative patients suffering from moderate to severe pain. Whereas, longterm use of opioids for chronic non-cancer pain has been reported to be associated with little improvement of pain, physical functioning, and sleep quality when compared to a placebo. ${ }^{1,2}$ Additionally, there was similar improvement in pain compared to non-opioid medications (non-steroidal anti-inflammatory drugs (NSAIDs), tricyclic antidepressants, and synthetic cannabinoids). ${ }^{1-3}$ Furthermore, long-term opioid use in non-cancer patients was found to be strongly associated with mortality (odd ratio (OR); 2-3.7, $95 \% \mathrm{Cl} ; 1.8-5.1)^{4,5}$, morbidity; including, cardiovascular problems myocardial infarction $(\mathrm{MI})$, respiratory problems (OR; 2.3, 95\% Cl; 2.2-2.4) , $^{5,6}$ and increased opioid side effects (vomiting, drowsiness, constipation, dizziness, nausea, dry mouth, and pruritus). ${ }^{1,3,5}$

Over the last 10 years, many studies have shown opioid prescribing and incident of long term opioid use among non-cancer pain as having increased by approximately 16.0-40.0\%. ${ }^{7,8}$ Among elective orthopedic surgery, spinal fusion surgery was associated with postoperative opioid abuse and opioid dependence. ${ }^{5}$ Compared with other major surgeries, the incidence of prolong postoperative opioid use after spinal surgery was more than $10.0 \%$, which again is higher than any other major surgery, for which the incidence of prolong postoperative opioid use is less than $8.0 \% .^{9-12}$

These previous studies have identified risk factors associated with prolonged postoperative opioids use; including, a young age, poor socioeconomic status, preoperative opioids use, and preoperative depression or anxiety. ${ }^{3,9,10,13,14}$ However, all of these studies lack information regarding intraoperative and early postoperative pain management while patients were still staying in the hospital.
In addition, most of these studies did not specify whether the study subjects were cancer or non-cancer patients.

Based on the aforementioned knowledge, prolonged opioids use for non-cancer patients has to be minimized. Nonetheless, knowledge on prolonged opioids use among non-cancer patients is still limited. Therefore, this study aimed to identify factors associated with prolonged postoperative opioid use among non-cancer patients undergoing spinal surgery. This information will assist physicians to improve their strategies to minimize risks associated with prolong opioids use in non-cancer patients; either prior to or after surgery.

\section{Material and Methods}

Data Source and Study design: The study design was approved by the Human Research Ethics Committee of the Faculty of Medicine, Prince of Songkla University. After which, the medical records from the hospital information system of Songklanagarind Hospital were retrospectively reviewed. We used a combination of anesthetic, inpatient, and outpatient data. We extracted medical records of all patients who underwent spinal surgery (dissectomy, laminectomy, decompressive and fusion, fusion, scoliosis correction, microdissectomy, or percutaneous dissectomy) at Songklanagarind Hospital; from January 2014 to January 2019, taken from anesthetic records that have been uploaded to the hospital information system. In order to be included in the study, patients were required to be noncancer patients, neither malignant nor benign, and have had completed follow-up at Songklanagarind Hospital for at least 3 months postoperatively. Patients whom underwent pain procedure (epidural steroid injection), lumbar puncture, or patients with opioids prescribed after surgery during the follow-up period without being prescribed as homemedication were excluded from the study. Traumatic patients with associated major injury (cardiovascular, thoracic, abdominal, intracerebral and other fractures; except spinal fracture and computed tomography negative intracerebral 
injury), with the exception of spinal cord injury and spinal fracture, were excluded. In addition, patients with reoperative surgery within the same admission period were excluded from the study. The medical records were retrospectively reviewed by the main researcher for demographic data, preoperative diagnosis, preoperative medications used, type of surgery, site of surgery, level of surgery, duration of surgery, intraoperative pain controlled, seven days postoperative pain controlled, seven days postoperative pain score, home-medications, pain score on discharge day, pain score and opioids prescribed at the out-patient unit. The data was then filed in the data record form using a nonidentified number. Patients having opioids prescription as home-medication after spinal surgery, and continual opioids prescribing of more than 3 months after spinal surgery, were defined as patients with prolonged postoperative opioids usage. Other patients were classified into either no opioid used since discharge, or opioids used $\leq 3$ months since discharge.

The outcome variable was postoperative opioids use. The independent variables included: gender, age, weight, height, education, patient salary, co-existing disease, previous substances or opioids used (within 1 year preoperatively), preoperative diagnosis, type of spinal surgery, surgical site, level of surgery, duration of surgery, intraoperative opioids, other analgesic drugs used, and pain score during the pre-operative period, post-operative period and after discharge.

Statistical analysis was performed using the $\mathrm{R}$ program. All statistical tests were two-tailed and a p-value of less than 0.05 was defined as statistically significance. The patient's characteristics, which are categorical variables, were demonstrated as percentage and continuous variables were presented as mean and standard deviation or median and interquartile range. The characteristics of patients who did or did not exhibit prolonged postoperative opioid usage were compared using two-sample t-test for normally distributed data and the Willcoxon rank-sum test for nonnormally distributed data. The $\times 2$ test or Fisher exact test was used to compare the categorical variables between the groups (prolonged and not prolonged postoperative opioid use). The association of independent variables with prolonged postoperative opioid use at three months was assessed using univariate analysis. Based on the findings from the univariate analysis, a multivariable multinomial logistic regression model was constructed to identify independent factors associated with prolonged postoperative opioid use.

\section{Results}

In the time period of the study, there were 500 medical records retrospectively reviewed; most of these were middle-aged to elderly patients. The distribution of each of the independent variables is presented in Table 1. There were 228 (45.6\%) patients aged between 41-60 years and $171(34.2 \%)$ patients were older than 60 years of age. According to the $\mathrm{WHO}$ definition, only 37 patients $(7.4 \%)$ were obese (body mass index $\left.\geq 30 \mathrm{~kg} / \mathrm{m}^{2}\right)$. Nearly half of the patients (201 patients, 40.2\%) did not graduated compulsory education (Mattayom 3). There were 99 patients (19.8\%) who got paid less than the national minimum wage (300 baht per day or 9,000 baht per month). Most of the patients were non-smokers (353 patients, 70.6\%) and nonalcohol drinkers (409 patients, 81.8\%). About 21 patients $(4.2 \%)$ had substances abuse within 1 year preoperatively. Gabapentinoids (71.0\%) and NSAIDs (54.6\%) were mostly used for preoperative pain control compared with other pain medications. Dose ranges of preoperative gabapentin were $100-3,600 \mathrm{mg} /$ day and pregabalin was 75-150 mg/ day. More than half of the patients (333 patients, 66.6\%) were opioid naive before surgery and 167 patients (33.4\%) were prescribed opioids for pain control before surgery. 
Table 1 Characteristics of patients undergoing spinal surgery

$$
(n=500)
$$

\begin{tabular}{|c|c|c|}
\hline Variables & Number & $\%$ \\
\hline \multicolumn{3}{|l|}{ Gender } \\
\hline Male & 221 & 44.2 \\
\hline Female & 279 & 55.8 \\
\hline \multicolumn{3}{|l|}{ Age (years) } \\
\hline$<20$ & 26 & 5.2 \\
\hline $20-40$ & 75 & 15.0 \\
\hline $41-60$ & 228 & 45.6 \\
\hline $61-80$ & 164 & 32.8 \\
\hline$>80$ & 7 & 1.4 \\
\hline \multicolumn{3}{|l|}{ BMI $\left(\mathrm{kg} / \mathrm{m}^{2}\right)$} \\
\hline$<18.50$ & 37 & 7.4 \\
\hline $18.50-24.99$ & 248 & 49.6 \\
\hline $25.00-29.99$ & 178 & 35.6 \\
\hline$\geq 30.00$ & 37 & 7.4 \\
\hline \multicolumn{3}{|l|}{ Education } \\
\hline <Mattayom 3 (grade 9) & 201 & 40.2 \\
\hline >Mattayom 3 (grade 9) & 91 & 18.2 \\
\hline Bachelor's degree & 117 & 23.4 \\
\hline Master's degree & 19 & 3.8 \\
\hline Doctoral's degree & 3 & 0.6 \\
\hline No data & 69 & 13.8 \\
\hline \multicolumn{3}{|l|}{ Patient salary (Baht/month) } \\
\hline$<9,000$ & 99 & 19.8 \\
\hline $9,000-20,000$ & 61 & 12.2 \\
\hline $20,001-40,000$ & 86 & 17.2 \\
\hline $40,001-60,000$ & 26 & 5.2 \\
\hline$>60,000$ & 6 & 1.2 \\
\hline No data & 222 & 44.4 \\
\hline \multicolumn{3}{|l|}{ Smoking } \\
\hline Current smoker & 82 & 16.4 \\
\hline Non smoke & 353 & 70.6 \\
\hline Former smoker ( $\geq 1$ year cessation) & 65 & 13.0 \\
\hline \multicolumn{3}{|l|}{ Alcohol drinking } \\
\hline Regular (>3 days/week) & 25 & 5.0 \\
\hline No drinking & 409 & 81.8 \\
\hline Occasional drinking & 66 & 13.2 \\
\hline \multicolumn{3}{|l|}{$\begin{array}{l}\text { Preoperative substances abuse (within } \\
1 \text { year preoperatively) }\end{array}$} \\
\hline No & 479 & 95.8 \\
\hline Yes & 21 & 4.2 \\
\hline Amphetamine (yes) $^{*}$ & 2 & 0.4 \\
\hline Kratom (yes)* & 21 & 4.2 \\
\hline \multicolumn{3}{|l|}{ Co-existing diseases } \\
\hline No & 241 & 48.2 \\
\hline Yes & 259 & 51.8 \\
\hline Diabetic mellitus (yes)* & 61 & 12.2 \\
\hline Hypertension (yes) ${ }^{*}$ & 146 & 29.2 \\
\hline Dyslipidemia (yes)* & 114 & 22.8 \\
\hline Pulmonary diseases (yes) ${ }^{*}$ & 29 & 5.8 \\
\hline Depression (yes)* & 3 & 0.6 \\
\hline Anxiety (yes)* & 5 & 1.0 \\
\hline CSM (yes)* & 3 & 0.6 \\
\hline Lumbar spondylosis (yes)* & 6 & 1.2 \\
\hline
\end{tabular}

Table 1 (continued)

\begin{tabular}{|c|c|c|}
\hline Variables & Number & $\%$ \\
\hline \multicolumn{3}{|l|}{ Current medications } \\
\hline Paracetamol (yes) ${ }^{\star}$ & 146 & 29.2 \\
\hline NSAIDs (yes)* & 273 & 54.6 \\
\hline Cox 2 inhibitor (yes) ${ }^{*}$ & 84 & 16.8 \\
\hline TCA (yes) $)^{\star}$ & 1 & 0.2 \\
\hline Gabapentinoid (yes) $^{*}$ & 355 & 71.0 \\
\hline SSRI (yes)* & 88 & 17.6 \\
\hline SNRI (yes)* & 55 & 11.0 \\
\hline Muscle relaxant (yes) $)^{*}$ & 96 & 19.2 \\
\hline Sedative or hypnotic (yes) ${ }^{\star}$ & 25 & 5.0 \\
\hline Antipsychotic (yes)* & 2 & 0.4 \\
\hline \multicolumn{3}{|l|}{$\begin{array}{l}\text { Previous opioid use } \\
\text { (within } 1 \text { year preoperatively) }\end{array}$} \\
\hline No & 333 & 66.6 \\
\hline Yes & 167 & 33.4 \\
\hline Tramadol (yes) & 162 & 32.4 \\
\hline Morphine (yes) & 5 & 1.0 \\
\hline \multicolumn{3}{|l|}{ Diagnosis of spinal diseases } \\
\hline Degenerative & 374 & 74.8 \\
\hline Scoliosis & 32 & 6.4 \\
\hline Trauma or fracture & 62 & 12.4 \\
\hline Infection or inflammation & 32 & 6.4 \\
\hline \multicolumn{3}{|l|}{ Min. preoperative pain score } \\
\hline Painless (VNRS=0) & 318 & 63.6 \\
\hline Mild pain (VNRS=1-3) & 88 & 17.6 \\
\hline Moderate pain $(\mathrm{VNRS}=4-6)$ & 84 & 16.8 \\
\hline Severe pain (VNRS=7-10) & 10 & 2.0 \\
\hline \multicolumn{3}{|l|}{ Max. preoperative pain score } \\
\hline Painless (VNRS=0) & 150 & 30.0 \\
\hline Mild pain (VNRS=1-3) & 71 & 14.2 \\
\hline Moderate pain $(\mathrm{VNRS}=4-6)$ & 254 & 50.8 \\
\hline Severe pain (VNRS=7-10) & 25 & 5.0 \\
\hline \multicolumn{3}{|l|}{ Site of surgery } \\
\hline Cervical & 137 & 27.4 \\
\hline Thoracic & 21 & 4.2 \\
\hline Lumbar & 203 & 40.6 \\
\hline Coccyx & 1 & 0.2 \\
\hline Cervicothoracic & 8 & 1.6 \\
\hline Thoracolumbar & 54 & 10.8 \\
\hline Lumbosacral & 76 & 15.2 \\
\hline \multicolumn{3}{|l|}{ Type of surgery } \\
\hline Dissectomy & 14 & 2.8 \\
\hline Laminectomy & 30 & 6.0 \\
\hline Scoliosis correction & 32 & 6.4 \\
\hline Fusion & 41 & 8.2 \\
\hline Decompressive and fusion & 277 & 55.4 \\
\hline Minimal invasive surgery & 106 & 21.2 \\
\hline Re-operation (yes) & 32 & 6.4 \\
\hline $\begin{array}{l}\text { Level of surgery } \\
\text { (levels), median (IQR) }\end{array}$ & 3 & $2-4$ \\
\hline $\begin{array}{l}\text { Duration of operation } \\
\text { (minutes), median (IQR) }\end{array}$ & 240 & $160-335$ \\
\hline $\begin{array}{l}\text { Estimated blood loss } \\
(\mathrm{ml}) \text {, median (IQR) }\end{array}$ & 200 & $47.5-500$ \\
\hline
\end{tabular}


Table 1 (continued)

\begin{tabular}{|c|c|c|}
\hline Variables & Number & $\%$ \\
\hline $\begin{array}{l}\text { Intraop opioids consumption } \\
\text { (MME), median (IQR) }\end{array}$ & 22.5 & $15-34$ \\
\hline \multicolumn{3}{|l|}{$\begin{array}{l}\text { Postop opioid consumption } \\
\text { (MME/day), mean (S.D.) }\end{array}$} \\
\hline Postoperative day 0 & 13.8 & 8.7 \\
\hline Postoperative day 1 & 16.0 & 10.9 \\
\hline Postoperative day 2 & 12.1 & 8.3 \\
\hline Postoperative day 3 & 11.2 & 7.7 \\
\hline Postoperative day 4 & 10.2 & 7.2 \\
\hline Postoperative day 5 & 10.2 & 8.3 \\
\hline Postoperative day 6 & 10.1 & 7.8 \\
\hline Postoperative day 7 & 10.5 & 7.5 \\
\hline \multicolumn{3}{|l|}{ Min. discharge pain score } \\
\hline Painless (VNRS=0) & 233 & 46.6 \\
\hline Mild pain (VNRS=1-3) & 211 & 42.2 \\
\hline Moderate pain $(\mathrm{VNRS}=4-6)$ & 54 & 10.8 \\
\hline Severe pain (VNRS=7-10) & 2 & 0.4 \\
\hline \multicolumn{3}{|l|}{ Max. discharge pain score } \\
\hline Painless (VNRS=0) & 117 & 23.4 \\
\hline Mild pain (VNRS=1-3) & 218 & 43.6 \\
\hline Moderate pain $(\mathrm{VNRS}=4-6)$ & 139 & 27.8 \\
\hline Severe pain $($ VNRS $=7-10)$ & 2 & 5.2 \\
\hline $\begin{array}{l}\text { Lenght of hospital stay after } \\
\text { surgery (days) Median, IQR }\end{array}$ & 5 & $4-7$ \\
\hline
\end{tabular}

*=non mutually exclusive, CSM=cervical spondylotic myelopathy, TCA=tricyclic antidepressant, SSRI=selective serotonin reuptake inhibitor, SNRI=serotonin-norepinephrine reuptake inhibitor, Min. $=$ minimum, Max. $=$ maximum, IQR=interquartile range, $M M E=m g$ of morphine equivalent, S.D.=standard deviation, VNRS=verbal numerical rating scale, NSAIDs=non-steroidal anti-inflammatory drugs, Cox2=cyclooxygenase 2

Degenerative spinal disease was the most common diagnosis (373 patients, $74.8 \%$ ). Most of the patients (254 patients, 50.8\%), reported moderate pain severity (VNRS=4-6) for maximum preoperative pain score, 25 patients $(5.0 \%)$ reported severe pain severity (VNRS=710) and others reported painless (150 patients, 30.0\%) or mild (71 patients, $14.2 \%$ ) pain severity (VNRS $=0-3$ ). For intraoperative data, spinal decompression and fusion was the most common type of surgery (277 patients, $55.4 \%$ ), following by minimal invasive surgery; such as, microdissection or percutaneous dissection (106 patients,
$21.2 \%)$. The median of surgical level was 3 levels (IQR=24). The median of surgical duration was 240 minutes (IQR=160-335). The median of the dose of intraoperative opioid consumption was $22.5 \mathrm{mg}$ of morphine equivalent (MME) (IQR=15-34). For postoperative data, the opioid consumption during postoperative day 1 to 7 were 16.0, 12.1, 11.2, 10.2, 10.2, 10.1, and 10.5 MME, respectively. A total of 335 patients $(67.0 \%)$ were discharged from the hospital without any or only mild pain severity (VNRS=03) for maximum pain score. While, 139 patients $(27.8 \%)$ were discharged with moderate pain severity $(\mathrm{VNRS}=4-6)$ and 26 patients $(5.2 \%)$ were discharged with severe pain severity (VNRS=7-10) for maximum pain score. Total length of hospital stay after surgery was 5 days (IQR=4-7).

Table 2 shows analgesic drugs prescribed after hospital discharge and during the postoperative followup period. From this, 152 patients $(30.4 \%)$ had opioid prescriptions as home-medication and from all of these prescriptions, the opioid given was 100\% tramadol. Among the patients with opioid prescriptions as home-medication, 65 patients $(42.8 \%)$ had prolonged (>3 months) postoperative opioid usage after spinal surgery and 87 patients (57.2\%) had opioid usage after spinal surgery; but this was not prolonged by more than 3 months postoperatively. There were 458 patients $(91.6 \%)$ who had multimodal analgesics prescriptions as home-medication. Among 152 patients who received opioids as home medication, there were 120 patients receiving both opioids and gabapentinoids.

A multivariable multinomial logistic regression model was constructed to identify independent factors associated with prolonged postoperative opioid use (Table 3). Compared with patients without opioid usage after hospital discharge, the factors associated with prolonged (>3 months) postoperative opioids use included: preoperative opioids used (relative risk (RR), 47.65; 95\% Cl, 17.67128.49; $p$-value $=0.000$ ), and length of hospital stay after 
Table 2 Analgesic drugs prescribed during hospital discharge and follow-up period $(n=500)$

\begin{tabular}{|c|c|c|}
\hline Analgesic drugs prescribed & Number & $\%$ \\
\hline Opioid prescription as home-medication (yes) & 152 & 30.4 \\
\hline Tramadol & 152 & 30.4 \\
\hline Dose around the clock & 50 & 32.9 \\
\hline Dose prn & 102 & 67.1 \\
\hline \multicolumn{3}{|l|}{ Other analgesic drugs prescription at discharge } \\
\hline Paracetamol (yes)* & 411 & 86.2 \\
\hline NSAIDs (yes)* & 256 & 51.2 \\
\hline Cox 2 inhibitor (yes)* & 90 & 18.0 \\
\hline Gabapentinoid (yes)* & 301 & 60.2 \\
\hline SSRI (yes)* & 36 & 7.2 \\
\hline SNRI (yes)* & 40 & 8.0 \\
\hline Multimodal analgesics prescription as home-medication (yes) & 458 & 91.6 \\
\hline \multicolumn{3}{|l|}{ Postoperative opioids use } \\
\hline No opioid use since discharge & 348 & 69.6 \\
\hline Opioid used $\leq 3$ months since discharge & 87 & 17.4 \\
\hline Opioid used $>3$ months since discharge & 65 & 13.0 \\
\hline
\end{tabular}

*=non mutually exclusive, SSRI=selective serotonin reuptake inhibitor, SNRI=serotonin-norepinephrine reuptake inhibitor, NSAIDs=nonsteroidal anti-inflammatory drugs, Cox2=cyclooxygenase 2

surgery (RR, 1.07; 95\% Cl, 1.01-1.14; p-value=0.037); whereas, patients with preoperative gabapentinoids use were found to have a decreased risk for prolonged (>3 months) postoperative opioid use; as compared with patients without opioid usage after hospital discharge (RR, 0.33; $95 \% \mathrm{Cl}, 0.13-0.83 ; \mathrm{p}$-value=0.019).

Compared with patients without opioids used after hospital discharge, factors associated with postoperative opioids use ( $\leq 3$ months) included: preoperative substance abuse (RR, 3.97; 95\% Cl, 1.30-12.14; p-value=0.016), preoperative opioids used $(\mathrm{RR}, 8.58$; $95 \% \mathrm{Cl}, 4.52-$ 16.25; $p$-value=0.000), and level of surgery (RR, 1.33; $95 \% \mathrm{Cl}, 1.10-1.62 ; \mathrm{p}$-value $=0.004)$. Whereas, patients with preoperative gabapentinoids used, and undergoing minimal invasive surgery were found to have a decreased risk for postoperative opioid use ( $\leq 3$ months) compared with patients without opioids used after hospital discharge (RR, 0.47; 95\% Cl, 0.23-0.96; p-value=0.037, and RR, 0.28; 95\% Cl, 0.08-0.94; p-value=0.039, respectively).
Moreover, patients with co-existing pulmonary diseases (RR, 1.07; 95\% Cl, 1.01-1.14; p-value=0.037), preoperative opioid usage $(\mathrm{RR}, 47.65 ; 95 \% \mathrm{Cl}$, 17.67128.49; $p$-value=0.000), intraoperative opioid consumption (RR, 1.01; 95\% Cl, 1.01-1.02; p-value=0.008), and length of hospital stay after surgery $(\mathrm{RR}, 1.12 ; 95 \% \mathrm{Cl}, 1.03-$ $1.21 ; p$-value $=0.007$ ) were factors which increase the risk of prolonged (>3 months) postoperative opioid usage comparing with non-prolonged ( $\leq 3$ months) postoperative opioid use.

\section{Discussion}

In this study, 152 non-cancer patients (30.4\%) had opioid prescriptions postoperatively as home-medication. Among 152 patients, 65 patients (42.8\%) had prolonged (>3 months) postoperative opioid use after surgery. So, the incidence of prolonged postoperative opioids use in our study was $13.0 \%$, from a total of 500 patients. Our incidence was higher than the findings published by Schoenfeld ${ }^{9}$, for 
Table 3 Multivariate analysis demonstrating risk factors associated with prolonged opioid use postoperatively $(n=500)$

\begin{tabular}{|c|c|c|c|c|c|}
\hline \multirow[b]{2}{*}{ Factors } & \multirow[b]{2}{*}{ Levels } & \multirow[b]{2}{*}{ Number (\%) } & \multicolumn{3}{|c|}{ Relative risk reduction $(95 \% \mathrm{Cl})$} \\
\hline & & & $\begin{array}{l}\text { Opioid used } \\
\leq 3 \text { months vs } \\
\text { No opioid used }\end{array}$ & $\begin{array}{l}\text { Opioid used } \\
>3 \text { months vs } \\
\text { No opioid used }\end{array}$ & $\begin{array}{l}\text { Opioid used } \\
>3 \text { months vs } \\
\leq 3 \text { months }\end{array}$ \\
\hline \multirow{2}{*}{$\begin{array}{l}\text { Preoperative substances } \\
\text { abuse }\end{array}$} & No & $479(95.8)$ & 1 & 1 & 1 \\
\hline & Yes & $21(4.2)$ & $\begin{array}{l}3.97 \\
(1.30-12.14)^{*}\end{array}$ & $\begin{array}{l}0.99 \\
(0.15-6.55)\end{array}$ & $\begin{array}{l}0.25 \\
(0.40-1.53)\end{array}$ \\
\hline \multirow{2}{*}{$\begin{array}{l}\text { Co-existing diseases as } \\
\text { pulmonary diseases }\end{array}$} & No & $471(94.2)$ & 1 & 1 & 1 \\
\hline & Yes & $29(5.8)$ & $\begin{array}{l}0.67 \\
(0.19-2.30)\end{array}$ & $\begin{array}{l}3.08 \\
(0.87-10.88)\end{array}$ & $\begin{array}{l}4.62 \\
(1.06-20.05)^{\star}\end{array}$ \\
\hline \multirow[t]{2}{*}{ Previous opioid use } & No & $333(66.6)$ & 1 & 1 & 1 \\
\hline & Yes & $167(33.4)$ & $\begin{array}{l}8.58 \\
(4.52-16.25)^{*}\end{array}$ & $\begin{array}{l}47.65 \\
(17.67-128.49)^{\star}\end{array}$ & $\begin{array}{l}5.56 \\
(1.93-15.97)^{\star}\end{array}$ \\
\hline \multirow{2}{*}{$\begin{array}{l}\text { Preoperative Cox } 2 \text { inhibitors } \\
\text { use }\end{array}$} & No & $416(83.2)$ & 1 & 1 & 1 \\
\hline & Yes & $84(16.8)$ & $\begin{array}{l}0.61 \\
(0.26-1.41)\end{array}$ & $\begin{array}{l}0.38 \\
(0.14-1.01)\end{array}$ & $\begin{array}{l}0.63 \\
(0.21-1.87)\end{array}$ \\
\hline \multirow{2}{*}{$\begin{array}{l}\text { Preoperative gabapentinoids } \\
\text { use }\end{array}$} & No & $145(29.0)$ & 1 & 1 & 1 \\
\hline & Yes & $355(71.0)$ & $\begin{array}{l}0.47 \\
(0.23-0.96)^{\star}\end{array}$ & $\begin{array}{l}0.33 \\
(0.13-0.83)^{*}\end{array}$ & $\begin{array}{l}0.71 \\
(0.27-1.90)\end{array}$ \\
\hline \multirow{2}{*}{$\begin{array}{l}\text { Preoperative muscle relaxants } \\
\text { use }\end{array}$} & No & $404(80.2)$ & 1 & 1 & 1 \\
\hline & Yes & $96(19.2)$ & $\begin{array}{l}0.51 \\
(0.24-1.09)\end{array}$ & $\begin{array}{l}1.13 \\
(0.50-2.59)\end{array}$ & $\begin{array}{l}2.20 \\
(0.85-5.70)\end{array}$ \\
\hline \multirow[t]{4}{*}{ Diagnosis of spinal diseases } & Degenerative diseases & $374(74.8)$ & 1 & 1 & 1 \\
\hline & Scoliosis & $32(6.4)$ & $\begin{array}{l}0.19 \\
(0.02-1.49)\end{array}$ & - & - \\
\hline & Trauma or fracture & $62(12.4)$ & $\begin{array}{l}1.79 \\
(0.70-4.62)\end{array}$ & $\begin{array}{l}2.11 \\
(0.53-8.35)\end{array}$ & $\begin{array}{l}1.18 \\
(0.26-5.30)\end{array}$ \\
\hline & Infection or inflammation & $32(6.4)$ & $\begin{array}{l}1.54 \\
(0.49-4.85)\end{array}$ & $\begin{array}{l}0.51 \\
(0.13-2.00)\end{array}$ & $\begin{array}{l}0.33 \\
(0.84-1.31)\end{array}$ \\
\hline \multirow[t]{4}{*}{ Type of surgery } & $\begin{array}{l}\text { Decompression } \\
\text { (dissectomy or } \\
\text { laminectomy) }\end{array}$ & $44(8.8)$ & 1 & 1 & 1 \\
\hline & $\begin{array}{l}\text { Decompressive fusion or } \\
\text { scoliosis correction }\end{array}$ & $309(61.8)$ & $\begin{array}{l}1.36 \\
(0.55-3.36)\end{array}$ & $\begin{array}{l}3.68 \\
(0.88-15.30)\end{array}$ & $\begin{array}{l}2.70 \\
(0.61-11.96)\end{array}$ \\
\hline & Fusion & $41(8.2)$ & $\begin{array}{l}0.84 \\
(0.21-3.38)\end{array}$ & $\begin{array}{l}3.72 \\
(0.62-22.23)\end{array}$ & $\begin{array}{l}4.41 \\
(0.64-30.57)\end{array}$ \\
\hline & Minimal invasive surgery & $106(21.2)$ & $\begin{array}{l}0.28 \\
(0.08-0.94)^{*}\end{array}$ & $\begin{array}{l}1.55 \\
(0.32-7.60)\end{array}$ & $\begin{array}{l}5.52 \\
(0.92-33.16)\end{array}$ \\
\hline Level of surgery & Continuous & & $\begin{array}{l}1.33 \\
(1.10-1.62)^{\star}\end{array}$ & $\begin{array}{l}1.25 \\
(1.00-1.58)\end{array}$ & $\begin{array}{l}0.94 \\
(0.75-1.17)\end{array}$ \\
\hline $\begin{array}{l}\text { Intraoperative opioids } \\
\text { consumption }\end{array}$ & Continuous & & $\begin{array}{l}0.99 \\
(0.99-1.00)\end{array}$ & $\begin{array}{l}1.00 \\
(1.00-1.01)\end{array}$ & $\begin{array}{l}1.01 \\
(1.01-1.02)^{*}\end{array}$ \\
\hline Lenght of hospital stay & Continuous & & $\begin{array}{l}0.96 \\
(0.89-1.03)\end{array}$ & $\begin{array}{l}1.07 \\
(1.01-1.14)^{\star}\end{array}$ & $\begin{array}{l}1.12 \\
(1.03-1.21)^{*}\end{array}$ \\
\hline
\end{tabular}

${ }^{*} \mathrm{p}$-value $<0.005$

$\mathrm{Cl}=$ confidence interval, Cox2=cyclooxygenase2 
which the incidence of prolonged ( $>3$ months) postoperative opioids use was $3.0 \%$, and lower than the findings published by Pugely ${ }^{10}$, Duun ${ }^{11}$, and Connolly ${ }^{15}$, in which the incidence were $50.0 \%, 43.0 \%$, and $28.0 \%$, respectively.

\section{Previous opioids used (within 1 year) before} surgery

Our study showed that patients with previous opioid usage were strongly associated with prolonged (>3 months) postoperative opioid use (RR, 47.65; 95\% Cl, 17.67-128.49) and postoperative opioid use $\leq 3$ months (RR, 8.58; 95\% Cl, 4.52-16.25), compared with patients without opioid usage after hospital discharge. Our findings were consistent with previous studies published by Pugely $^{10}$, Dunn ${ }^{11}$, Adogwa ${ }^{16}$, Rosenthal ${ }^{17}$, and Connolly ${ }^{15}$ that investigated risk factors associated with long-term opioid use following spinal surgery. Due to the association between previous opioids used and prolonged postoperative opioids used as shown in several studies; including our study, this could be a result of higher incidence of prolonged postoperative opioid use among the studies of Pugely ${ }^{10}$, Duun $^{11}$, and Connolly ${ }^{15}$, because there were more than $50.0 \%$ of patients in each study that were non-opioid naïve before surgery; whereas, there were only $33.0 \%$ that were non-opioid naïve before surgery in our study.

The strategies to reduce preoperative opioids used among non-cancer patients should be considered to reduce the risk of prolonged postoperative opioid use in non-cancer patients undergoing spinal surgery.

\section{Other medications used perioperative}

According to our knowledge, our study is the first study finding preoperative gabapentinoids use reduced, not only the risk of prolonged (>3 months) postoperative opioid use (RR, 0.33; 95\% Cl, 0.13-0.83), but also the risk of postoperative opioids use $\leq 3$ months (RR, 0.47; $95 \% \mathrm{Cl}$,
0.23-0.96), compared with patients without opioids used after hospital discharge. This hypothesis suggests that more than $60.0 \%$ of postoperative spinal surgery patients suffer from neuropathic pain ${ }^{18}$, which could be eased by gabapentinoids. Furthermore, gabapentinoids are capable of reducing central sensitization by inhibiting calcium channel activation at the dorsal horn neurons; leading to the reduction of incidence of prolonged postoperative pain as a result of decreasing prolonged postoperative opioid use.

A previous study, published by Clarke $^{13}$, did not include information reqarding preoperative gabapentinoids use, but their results showed patients with preoperative use of either benzodiazepine, or selective serotonin reuptake inhibitor (SSRI) was associated with prolonged (>3 months) opioid use after major surgery. On the other hand, there is no association between preoperative use with either sedative-hypnotics, or SSRI with prolonged postoperative opioid use in our study.

According to the study of Verret ${ }^{19}$, although the study concluded that the perioperative use of gabapentinoids had no clinically analgesic effect (no clinically significance in pain intensity), the study stated that the cumulative opioid dose administered within 24, 48 and 72 hours after surgery in perioperative patients using gabapentinoids is lower than the dose administrated in the placebo group. Furthermore, the study also suggested that perioperative use of gabapentinoids had no preventive effect on chronic opioid use; which is different from our results. This is because, the study explored only one trial; which only included 410 participants, to evaluate the risk of prolonged opioid use; which is considered to be too small for conclusive research. Therefore, many more studies for chronic opioid usage and gabapentinoids is required.

In agreement with the systematic review and metaanalysis, published by Busse ${ }^{1}$, reported anticonvulsants 
(gabapentinoids) showed similar improvements in pain and physical functioning compared with opioids among patients with chronic non-cancer pain. We suggest the use of gabapentinoids for preoperative pain control in non-cancer patients suffering from spinal pain; especially in high risk of opioid-use disorder patients. Accordingly, this is to reduce not only the risk of prolonged postoperative opioid use, but also the incidence of preoperative opioids used among non-cancer patients scheduled for spinal surgery.

\section{Length of hospital stay after surgery}

Our study reported that the length of hospital stay after surgery was associated with risk of prolonged (>3 months) postoperative opioid use. (RR, 1.07; $95 \% \mathrm{Cl}$, 1.01-1.14). Our results were consistent with the previous study published by Adogwa ${ }^{16}$, which showed that the length of hospital stay was associated with prolonged ( $>1$ year) postoperative opioid use after spinal fusion. However, the length of hospital stay after surgery was 6 days for prolonged (>3 months) postoperative opioid usage group and 5 days for non-prolonged postoperative opioid usage group. Even though there is a statically significant difference between these two groups, the gap different is only 1 day. One day difference of hospital stay can be either due to medical or non-medical reasons. Therefore, it may be difficult for clinical relevance to use length of hospital stay as a risk factor for predicting prolonged postoperative opioids use in non-cancer patients undergoing spinal surgery.

\section{Age}

Descriptive statistics of demographics data shows that most of the patients in our study were middle-aged (41-60 years) to elderly (>60 years) patients. This was similar to the patients in previous studies published by Clarke $^{13}$, Pugely ${ }^{10}$, and Adogwa ${ }^{16}$ These results can be according to the prevalence rate of spinal diseases, which is higher in adults than in children or adolescents ${ }^{20,21}$, and for which peaks in an increase between ages of 35 and 55 . $^{22}$ Together with most spinal diseases being associated with degenerative change in older people, and mainly the treatment being pain control with analgesics. Spinal surgery remains the last option when all other strategies; including, rehabilitation and life-style modification have failed. Therefore, patients in our study, which included patients who underwent spinal surgery, were middle-aged to elderly patients, more so than children or adolescents.

According to our knowledge, elderly patients consumed lower analgesic drug doses comparing with younger patients, because of changes in pharmacodynamics and pharmacokinetics ${ }^{23,24}$, due to shrinkage of the brain, decreased drug metabolization by the liver, and decreased drug excretion by renal. We hypothesized that younger patients that require more analgesics may be a risk factor associated with prolonged postoperative opioid use compared with elderly patients.

While, previous studies published by Pugely ${ }^{10}$, and Adogwa $^{16}$ showed a younger age ( $<50$ years, and $66-85$ years, respectively) is a risk factor associated with prolonged postoperative opioid use after spinal surgery, our study did not show this. Although, there is no statically significant association related to age between prolonged ( $>3$ months) and non-prolonged postoperative opioid use, the patients in our study from our descriptive data; as presented in Table 4 , showed there were more young patients (18-60 years) than elderly patients (>60 years) among patients who had prolonged (>3 months) postoperative opioid usage after spinal surgery.

\section{Preoperative substances abuse}

There were 21 patients $(4.2 \%)$ that reported previous substances use before surgery in our study. While, there is statically significant data showing patients with preoperative 
Table 4 Univariate analysis demonstrating risk factors associated with prolonged opioid use postoperatively $(n=500)$

\begin{tabular}{|c|c|c|c|c|}
\hline Variable & $\begin{array}{l}\text { No opioid used } \\
\text { since discharge }\end{array}$ & $\begin{array}{l}\text { Opioid used } \\
\leq 3 \text { months } \\
\text { since discharge }\end{array}$ & $\begin{array}{l}\text { Opioid used } \\
>3 \text { months } \\
\text { since discharge }\end{array}$ & $p$-value \\
\hline Total $n$ & $348(69.6 \%)$ & $87(17.4 \%)$ & $65(13.0 \%)$ & \\
\hline \multicolumn{4}{|l|}{ Gender } & 0.590 \\
\hline Male & $159(71.9 \%)$ & $35(15.8 \%)$ & $27(12.2 \%)$ & \\
\hline Female & $189(67.7 \%)$ & $52(18.6 \%)$ & $38(13.6 \%)$ & \\
\hline \multicolumn{4}{|l|}{ Age (years) } & 0.095 \\
\hline$<20$ & $19(73.1 \%)$ & $7(26.9 \%)$ & $0(0.0 \%)$ & \\
\hline $20-40$ & $54(72.0 \%)$ & $15(20.0 \%)$ & $6(8.0 \%)$ & \\
\hline $41-60$ & $161(70.6 \%)$ & $36(15.8 \%)$ & $31(13.6 \%)$ & \\
\hline $61-80$ & $111(67.7 \%)$ & $28(17.1 \%)$ & $25(15.2 \%)$ & \\
\hline$>80$ & $3(42.9 \%)$ & $1(14.3 \%)$ & $3(42.9 \%)$ & \\
\hline \multicolumn{4}{|l|}{ BMI $\left(\mathrm{kg} / \mathrm{m}^{2}\right)$} & 0.755 \\
\hline$<18.50$ & 29 (78.4\%) & $4(10.8 \%)$ & $4(10.8 \%)$ & \\
\hline $18.50-24.99$ & $168(67.7 \%)$ & $43(17.3 \%)$ & $37(14.9 \%)$ & \\
\hline $25.00-29.99$ & $124(69.7 \%)$ & $33(18.5 \%)$ & $21(11.8 \%)$ & \\
\hline$\geq 30.00$ & $27(73.0 \%)$ & $7(18.9 \%)$ & $3(8.1 \%)$ & \\
\hline \multicolumn{4}{|l|}{ Education } & 0.016 \\
\hline <Mattayom 3 (grade 9) & $126(62.7 \%)$ & $41(20.4 \%)$ & $34(16.9 \%)$ & \\
\hline 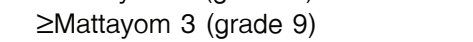 & $68(74.7 \%)$ & $13(14.3 \%)$ & $10(11.0 \%)$ & \\
\hline Bachelor's degree & $94(80.3 \%)$ & $18(15.4 \%)$ & $5(4.3 \%)$ & \\
\hline Master's degree & $15(78.9 \%)$ & $2(10.5 \%)$ & $2(10.5 \%)$ & \\
\hline Doctoral's degree & $2(66.7 \%)$ & $0(0.0 \%)$ & $1(33.3 \%)$ & \\
\hline \multicolumn{4}{|l|}{ Patient salary (Baht/month) } & 0.084 \\
\hline$<9,000$ & $69(69.7 \%)$ & $19(19.2 \%)$ & $11(11.1 \%)$ & \\
\hline $9,000-20,000$ & $40(65.6 \%)$ & $12(19.7 \%)$ & $9(14.8 \%)$ & \\
\hline $20,001-40,000$ & $72(83.7 \%)$ & $11(12.8 \%)$ & $3(3.5 \%)$ & \\
\hline $40,001-60,000$ & $22(84.6 \%)$ & $1(3.8 \%)$ & $3(11.5 \%)$ & \\
\hline$>60,000$ & $5(83.3 \%)$ & $1(16.7 \%)$ & $0(0.0 \%)$ & \\
\hline \multicolumn{4}{|l|}{ Smoking } & 0.971 \\
\hline Current smoker & $55(67.1 \%)$ & $16(19.5 \%)$ & $11(13.4 \%)$ & \\
\hline Non smoke & $247(70.0 \%)$ & $61(17.3 \%)$ & $45(12.7 \%)$ & \\
\hline Former smoker ( $\geq 1$ year cessation) & $46(70.8 \%)$ & $10(15.4 \%)$ & $9(13.8 \%)$ & \\
\hline \multicolumn{4}{|l|}{ Alcohol drinking } & 0.412 \\
\hline Regular (>3 days/week) & $15(60.0 \%)$ & $7(28.0 \%)$ & $3(12.0 \%)$ & \\
\hline No drinking & $282(68.9 \%)$ & $72(17.6 \%)$ & $55(13.4 \%)$ & \\
\hline Occasional drinking & $51(77.3 \%)$ & $8(12.1 \%)$ & $7(10.6 \%)$ & \\
\hline \multicolumn{5}{|c|}{ Preoperative substances abuse (within 1 year } \\
\hline Yes & $11(52.4 \%)$ & $8(38.1 \%)$ & $2(9.5 \%)$ & \\
\hline No & $337(70.4 \%)$ & $79(16.5 \%)$ & $63(13.2 \%)$ & \\
\hline \multicolumn{4}{|l|}{ Co-existing diseases } & 0.238 \\
\hline Yes & $176(68.0 \%)$ & $43(16.6 \%)$ & $40(15.4 \%)$ & \\
\hline No & $172(71.4 \%)$ & $44(18.3 \%)$ & $25(10.4 \%)$ & \\
\hline \multicolumn{5}{|l|}{ Underlying diseases } \\
\hline Anxiety (yes)* & $4(80.0 \%)$ & $0(0.0 \%)$ & $1(20.0 \%)$ & 0.481 \\
\hline Depression (yes)* & $2(66.7 \%)$ & $1(33.3 \%)$ & $0(0.0 \%)$ & 0.650 \\
\hline Diabetic mellitus (yes)* & $44(72.1 \%)$ & $11(18.0 \%)$ & $6(9.8 \%)$ & 0.735 \\
\hline Hypertension (yes)* & $98(67.1 \%)$ & $26(17.8 \%)$ & $22(15.1 \%)$ & 0.644 \\
\hline Dyslipidemia (yes) ${ }^{*}$ & $88(77.2 \%)$ & $13(11.4 \%)$ & $13(11.4 \%)$ & 0.102 \\
\hline Pulmonary disease (yes)* & $19(65.5 \%)$ & $4(13.8 \%)$ & $6(20.7 \%)$ & 0.427 \\
\hline \multirow{2}{*}{\multicolumn{4}{|c|}{$\begin{array}{l}\text { Previous opioid use } \\
\text { (within } 1 \text { year preoperatively) }\end{array}$}} & \\
\hline & & & & $<0.001$ \\
\hline $\begin{array}{l}\text { Yes } \\
\text { No }\end{array}$ & $\begin{array}{l}68(40.7 \%) \\
280(84.1 \%)\end{array}$ & $\begin{array}{l}46(27.5 \%) \\
41(12.3 \%)\end{array}$ & $\begin{array}{l}53(31.7 \%) \\
12(3.6 \%)\end{array}$ & \\
\hline
\end{tabular}


Table 4 (continued)

\begin{tabular}{|c|c|c|c|c|}
\hline Variable & $\begin{array}{l}\text { No opioid used } \\
\text { since discharge }\end{array}$ & $\begin{array}{l}\text { Opioid used } \\
\leq 3 \text { months } \\
\text { since discharge }\end{array}$ & $\begin{array}{l}\text { Opioid used } \\
>3 \text { months } \\
\text { since discharge }\end{array}$ & p-value \\
\hline \multicolumn{5}{|l|}{ Current medications } \\
\hline Paracetamol (yes)* & $101(69.2 \%)$ & $23(15.8 \%)$ & $22(15.1 \%)$ & 0.605 \\
\hline NSAIDs (yes)* ${ }^{*}$ & $189(69.2 \%)$ & $41(15.0 \%)$ & $43(15.8 \%)$ & 0.065 \\
\hline Cox 2 inhibitor (yes) $)^{*}$ & $67(79.8 \%)$ & $10(11.9 \%)$ & $7(8.3 \%)$ & 0.085 \\
\hline Tricyclic antidepressant (yes)* & $1(100.0 \%)$ & $0(0.0 \%)$ & $0(0.0 \%)$ & 1 \\
\hline Gabapentinoid (yes)* $^{*}$ & $253(71.3 \%)$ & $55(15.5 \%)$ & $47(13.2 \%)$ & 0.212 \\
\hline SSRI (yes)* & $55(62.5 \%)$ & $19(21.6 \%)$ & $14(15.9 \%)$ & 0.280 \\
\hline SNRI (yes)* & $34(61.8 \%)$ & $13(23.6 \%)$ & $8(14.5 \%)$ & 0.362 \\
\hline Muscle relaxant (yes) ${ }^{\star}$ & $71(74.0 \%)$ & $12(12.5 \%)$ & $13(13.5 \%)$ & 0.370 \\
\hline Sedative or hypnotic (yes) ${ }^{*}$ & $15(60.0 \%)$ & $6(24.0 \%)$ & $4(16.0 \%)$ & 0.467 \\
\hline Antipsychotic (yes)* & $2(100.0 \%)$ & $0(0.0 \%)$ & $0(0.0 \%)$ & 1 \\
\hline \multicolumn{4}{|l|}{ Diagnosis of spinal diseases } & 0.005 \\
\hline Degenerative & $266(71.1 \%)$ & $59(15.8 \%)$ & 49 (13.1\%) & \\
\hline Scoliosis & $25(78.1 \%)$ & $7(21.9 \%)$ & $0(0.0 \%)$ & \\
\hline Trauma or fracture & $44(71.0 \%)$ & $11(17.7 \%)$ & $7(11.3 \%)$ & \\
\hline Infection or inflammation & $13(40.6 \%)$ & $10(31.2 \%)$ & $9(28.1 \%)$ & \\
\hline \multicolumn{4}{|l|}{ Min. preoperative pain score } & 0.183 \\
\hline Painless (VNRS=0) & $235(73.9 \%)$ & $49(15.4 \%)$ & $34(10.7 \%)$ & \\
\hline Mild pain (VNRS=1-3) & $56(63.6 \%)$ & $18(20.5 \%)$ & $14(15.9 \%)$ & \\
\hline Moderate pain $(\mathrm{VNRS}=4-6)$ & $52(61.9 \%)$ & $17(20.2 \%)$ & $15(17.9 \%)$ & \\
\hline Severe pain (VNRS=7-10) & $5(50.0 \%)$ & $3(30.0 \%)$ & $2(20.0 \%)$ & \\
\hline \multicolumn{4}{|l|}{ Max. preoperative pain score } & $<0.001$ \\
\hline Painless (VNRS=0) & $116(77.3 \%)$ & $25(16.7 \%)$ & $9(6.0 \%)$ & \\
\hline Mild pain $(\mathrm{VNRS}=1-3)$ & $53(74.6 \%)$ & $10(14.1 \%)$ & $8(11.3 \%)$ & \\
\hline Moderate pain $(\mathrm{VNRS}=4-6)$ & $169(66.5 \%)$ & $46(18.1 \%)$ & $39(15.4 \%)$ & \\
\hline Severe pain $($ VNRS $=7-10)$ & $10(40.0 \%)$ & $6(24.0 \%)$ & $9(36.0 \%)$ & \\
\hline \multicolumn{4}{|l|}{ Re-operation (yes) } & 0.113 \\
\hline Yes & $19(59.4 \%)$ & $5(15.6 \%)$ & $8(25.0 \%)$ & \\
\hline No & $329(70.3 \%)$ & $82(17.5 \%)$ & $57(12.2 \%)$ & \\
\hline \multicolumn{4}{|l|}{ Site of surgery } & 0.082 \\
\hline Cervical & $102(74.5 \%)$ & $20(14.6 \%)$ & $15(10.9 \%)$ & \\
\hline Thoracic & $13(61.9 \%)$ & $5(23.8 \%)$ & $3(14.3 \%)$ & \\
\hline Lumbar & $149(73.4 \%)$ & $32(15.8 \%)$ & $22(10.8 \%)$ & \\
\hline Coccyx & $1(100.0 \%)$ & $0(0.0 \%)$ & $0(0.0 \%)$ & \\
\hline Cervicothoracic & $3(37.5 \%)$ & $2(25.0 \%)$ & $3(37.5 \%)$ & \\
\hline Thoracolumbar & $30(55.6 \%)$ & $16(29.6 \%)$ & $8(14.8 \%)$ & \\
\hline Lumbosacral & $50(65.8 \%)$ & $12(15.8 \%)$ & $14(18.4 \%)$ & \\
\hline \multicolumn{4}{|l|}{ Type of surgery } & $<0.001$ \\
\hline Dissectomy & $9(64.3 \%)$ & $2(14.3 \%)$ & $3(21.4 \%)$ & \\
\hline Laminectomy & $23(76.7 \%)$ & $7(23.3 \%)$ & $0(0.0 \%)$ & \\
\hline Scoliosis correction & $25(78.1 \%)$ & $7(21.9 \%)$ & $0(0.0 \%)$ & \\
\hline Fusion & $26(63.4 \%)$ & $7(17.1 \%)$ & $8(19.5 \%)$ & \\
\hline Decompressive and fusion & $173(62.5 \%)$ & $58(20.9 \%)$ & $46(16.6 \%)$ & \\
\hline Minimal invasive surgery & $92(86.8 \%)$ & $6(5.7 \%)$ & $8(7.5 \%)$ & \\
\hline \multicolumn{4}{|l|}{$\begin{array}{l}\text { Level of surgery (levels), } \\
\text { median (IQR) }\end{array}$} & 0.001 \\
\hline median (IQR) & $2(2,3)$ & $3(2,4)$ & $3(2,4)$ & \\
\hline \multicolumn{4}{|l|}{ Duration of operation (minutes), } & $<0.001$ \\
\hline \multirow[b]{2}{*}{$\begin{array}{l}\text { Estimated blood loss (ml), } \\
\text { median (IQR) }\end{array}$} & $220(145,315)$ & $280(195,350)$ & $300(225,355)$ & \\
\hline & $150(20,400)$ & $300(100,700)$ & $400(50,800)$ & $<0.001$ \\
\hline \multirow{2}{*}{$\begin{array}{l}\text { Intraop opioids consumption } \\
\text { (MME), median (IQR) }\end{array}$} & & & & 0.193 \\
\hline & $22.5(14.0,32.5)$ & $22(16.8,30.0)$ & $27.5(17.5,42.5)$ & \\
\hline
\end{tabular}


Table 4 (continued)

\begin{tabular}{|c|c|c|c|c|}
\hline Variable & $\begin{array}{l}\text { No opioid used } \\
\text { since discharge }\end{array}$ & $\begin{array}{l}\text { Opioid used } \\
\leq 3 \text { months } \\
\text { since discharge }\end{array}$ & $\begin{array}{l}\text { Opioid used } \\
>3 \text { months } \\
\text { since discharge }\end{array}$ & $p$-value \\
\hline Min. discharge pain score & & & & $<0.001$ \\
\hline Painless (VNRS=0) & $178(76.4 \%)$ & $33(14.2 \%)$ & $22(9.4 \%)$ & \\
\hline Mild pain (VNRS=1-3) & $144(68.2 \%)$ & $33(15.6 \%)$ & $34(16.1 \%)$ & \\
\hline Moderate pain (VNRS=4-6) & $25(46.3 \%)$ & $20(37.0 \%)$ & $9(16.7 \%)$ & \\
\hline Severe pain $($ VNRS=7-10) & $1(50.0 \%)$ & $0(0.0 \%)$ & $1(50.0 \%)$ & \\
\hline Max. discharge pain score & & & & 0.011 \\
\hline Painless (VNRS=0) & $89(76.1 \%)$ & $19(16.2 \%)$ & $9(7.7 \%)$ & \\
\hline Mild pain $(\mathrm{VNRS}=1-3)$ & $156(71.6 \%)$ & $29(13.3 \%)$ & $33(15.1 \%)$ & \\
\hline Moderate pain $(\mathrm{VNRS}=4-6)$ & $91(65.5 \%)$ & 29 (20.9\%) & $19(13.7 \%)$ & \\
\hline Severe pain (VNRS=7-10) & $12(46.2 \%)$ & $10(38.5 \%)$ & $4(15.4 \%)$ & \\
\hline Lenght of hospital stay after & & & & $<0.001$ \\
\hline surgery (days) Median, IQR & $5(3,7)$ & $5(4,8)$ & $6(5,10)$ & \\
\hline
\end{tabular}

*=non mutually exclusive, SSRI=selective serotonin reuptake inhibitor, SNRI=serotonin-norepinephrine reuptake inhibitor, NSAIDs=non-steroidal anti-inflammatory drugs, Min.=minimum, Max.=maximum, Cox2=cyclooxygenase2, VNRS=verbal numerical rating scale, IQR= interquartile range

substances abuse increased the risk of postoperative opioid use $\leq 3$ months (RR, 3.97; 95\% Cl, 1.30-12.14). However, there is no statically significant correlation between this factor and prolonged (>3 months) postoperative opioids used compared with patients without opioids used after hospital discharge ( $R R, 0.99 ; 95 \% \mathrm{Cl}, 0.15-6.55)$. In contrast to our result, Pugely ${ }^{10}$ presented that history of drug dependent was a risk factor associated with prolonged (>1 year) postoperative opioids used after cervical spine surgery.

There was a similar prevalence of substance use before surgery between ours (4.2\%) and the study published by Pugely ${ }^{10}(4.2 \%)$. However, the incidence of prolonged postoperative opioids used was two times higher in the study published by Pugely ${ }^{10}$. The lower incidence of the main outcome could be the reason of its low power to detect significant correlation between preoperative substance abuse and prolonged (>3 months) postoperative opioids used in our study.

\section{Co-existing diseases}

Our study did not find that co-existing diseases; including depression or anxiety, as a risk factor associated with prolonged (>3 months) postoperative opioids used. On the other hand, previous studies published by Schoenfeld ${ }^{9}$, Pugely $^{10}$, Connolly ${ }^{15}$, and Anderson ${ }^{25}$ showed different results. Schoenfeld ${ }^{9}$ showed depression was significantly associated with decreased likelihood of discontinuing opioid use at 1, 3, and 6 months after spine surgery. Pugely ${ }^{10}$, Connolly $^{15}$, and Anderson ${ }^{18}$ also reported similar results, in that clinical depression or anxiety were risk factors for long term opioid use in spinal surgery patients.

Nowadays, even though we have easier access to medical care, not all patients who experience mental problems seek help from a doctor. Our study included information in regards to preoperative diagnosed of depression or anxiety. Patients who had symptoms, but were never diagnosed might go undetected and therefore be classified as non-depression or non-anxiety patients. As a result of, undetected preoperative, co-existing mental 
diseases, our results showed low prevalence of patients with depression $(0.6 \%)$ or anxiety $(1.0 \%)$; which might lead to an underestimation of the association between co-existing depression or anxiety, and prolonged postoperative opioids used in our study.

\section{Type of surgery}

Our study presented minimal invasive surgery as being associated with decreased risk of postoperative opioid use $\leq 3$ months (OR, 0.28; 95\% Cl, 0.08-0.94), but was not statically significantly associated with prolonged (>3 months) postoperative opioids used (OR, 1.55; 95\% Cl, 0.32-7.60). Our study reported similar results with study published by Schoenfeld ${ }^{9}$ that reported low-intensity surgical interventions were associated with a higher likelihood of discontinuing opioid use at 1, 3, and 6 months after spine surgery. While, a previous study published by Clarke $^{13}$ showed minimal invasive surgery decrease the risk of prolonged ( $>3$ months) postoperative opioids used after major surgery.

According to our knowledge, minimal invasive procedures have been shown to decrease soft-tissue injury, and pain compared with non-minimal invasive procedures. All of these reasons could be explanation as to why minimal invasive surgery is associated with decrease analgesic requirements.

There are limitations in our study. Most of them are according to our study design, which is a retrospective review. Some data are missing; including almost $45.0 \%$ of patient's salary, and $14.0 \%$ of patient's education, which may have had an effect on our analysis. Preoperative and postoperative opioids used were determined by medical reconciliation on the day of hospital admission, or opioid prescription on medical records from the out-patient unit; for which some were pro re nata (PRN) doses. Therefore this was a limitation, as we do not know the patient's actual opioid use. Most of the medical records that were retrospectively reviewed did not record data concerning characteristic of pain, pain at rest or movement; including side effects related to opioids. Our study did not explore the out-patients using gabapentinoids during postoperative follow up periods which might affect the use of postoperative opioids. According to the limitations in our study, we suggest prospective studies be considered to complete the unavailable data, as mentioned above.

\section{Conclusion}

To recognized morbidity and mortality related opioid therapy in non-cancer pain, we studied the risk factors associated with prolonged postoperative opioid use in non-cancer patients undergoing spinal surgery. We reported previous opioid use, preoperatively, as being a strong risk factor associated with prolonged postoperative opioid use as well as length of hospital stay after surgery. While, patients' with preoperative gabapentinoids use was associated with a decreased risk of prolonged postoperative opioid use in non-cancer patients undergoing spinal surgery. Identify patients for these factors and prevention could reduce the risks associated with prolonged postoperative opioid use as well as related morbidity and mortality in non-cancer spinal pain patients.

\section{Acknowledgement}

I would Iso like to thank Mr.Andrew Jonathan Tait, from the Office of International Affairs, for the English proof-reading of this manuscript. Finally, I am extremely grateful to my research assistant, Miss Walailuk Jitpiboon, for helping in the data processing and analysis.

\section{Conflict of interest}

I confirm that there are no conflicts of interest associated with this publication and there has been no significant financial support for this work. 


\section{References}

1. Busse JW, Wang L, Kamaleldin M, Craigie S, Riva JJ, Montoya L, et al. Opioids for Chronic Noncancer Pain: A Systematic Review and Meta-analysis. JAMA 2018;320:2448-60.

2. Martell BA, O’Connor PG, Kerns RD, Becker WC, Morales $\mathrm{KH}$, Kosten TR, et al. Systematic review: opioid treatment for chronic back pain: prevalence, efficacy, and association with addiction. Ann Intern Med 2007;146:116-27.

3. Jirarattanaphochi $\mathrm{K}$, Jung $\mathrm{S}$. Nonsteroidal anti-inflammatory drugs for postoperative pain management after lumbar spine surgery: a meta-analysis of randomized controlled trials. J Neuro Spine SPI 2019;9:22-31.

4. Gomes T, Mamdani MM, Dhalla IA, Paterson JM, Juurlink DN. Opioid dose and drug-related mortality in patients with nonmalignant pain. Arch Intern Med 2011;171:686-91.

5. Menendez ME, Ring D, Bateman BT. Preoperative opioid misuse is associated with increased morbidity and mortality and after elective orthopedic surgery. Clin Orthop Relat Res 2015; 473:2402-12.

6. Solomon DH, Rassen JA, Glynn RJ, Garneau K, Levin R, Lee $J$, et al. The comparative safetyof opioids for nonmalignant pain in older adults. Arch Intern Med 2010;170:1979-86.

7. Gomes T, Mamdani MM, Dhalla IA, Paterson JM, Juurlink DN. Trends in opioid use and dosing among socio-economically disadvantaged patients. Open Med 2011;5:e13-22.

8. Boudreau D, VonKorff M, Rutter CM, Saunders K, Ray GT, Sullivan MD, et al. Trends in long-term opioid therapy for chronic non-cancer pain. Pharmacoepidemiol Drug Saf 2009;18:1166-75.

9. Schoenfeld AJ, Nwosu K, Jiang W, Yau AL, Chaudhary MA, Scully RE, et al. Risk factors for prolonged opioid use following spine surgery, and the association with surgical intensity, among opioid-naive patients. J Bone Joint Surg Am 2017;99:1247-52.

10. Pugely AJ, Bedard NA, Kalakoti $P$, Hendrickson NR, Shillingford JN, Laratta JL, et al. Opioid use following cervical spine surgery: trends and factors associated with long-term use. Spine J 2018;18:1974-81.

11. Dunn LK, Yerra S, Fang S, Hanak MF, Leibowitz MK, Tsang S. Incidence and risk factors for chronic postoperative opioid use after major spine surgery: a cross-sectional study with longitudinal outcome. Anesth Analg 201;127:247-54.

12. Soneji N, Clarke HA, Ko DT, Wijeysundera DN. Risks of developing persistent opioid use after major surgery. JAMA Surg 2016;151:1083-4.
13. Clarke H, Soneji N, Ko DT, Yun L, Wijeysundera DN. Rates and risk factors for prolonged opioid use after major surgery: population based cohort study. BMJ 2014;348:1251.

14. Yang S, Werner BC. Risk factors for prolonged postoperative opioid use after spinal fusion for adolescent idiopathic scoliosis. J Ped Orthop 2019;39:500-4.

15. Connolly J, Javed Z, Raji MA, Chan W, Kuo YF, Baillargeon J. Predictors of long-term opioid use following lumbar fusion surgery. Spine 2017;42:1405-11.

16. Adogwa O, Davison MA, Vuong VD, Desai SA, Lilly DT, Moreno $J$, et al. Regional variation in opioid use after lumbar spine surgery. World Neurosurg 2019;121:e691-9.

17. Rosenthal BD, Suleiman LI, Kannan A, Edelstein AI, Hsu WK, Patel AA. Risk factors for prolonged postoperative opioid use after spine surgery: a review of dispensation trends from a state-run prescription monitoring program. J Am Acad Orthop Surg 2019;27:32-38.

18. Markman JD, Kress BT, Frazer M, Hanson R, Kogan V, Huang $\mathrm{JH}$. Screening for neuropathic characteristics in failed back surgery syndromes: challenges for guiding treatment. Pain Med 2015;16:520-30.

19. Verret M, Lauzier F, Zarychanski R, Perron C, Savard X, Pinard AM, et al. Perioperative use of gabapentinoids for the management of postoperative acute pain: a systematic review and meta-analysis. Anesthesiology 2020;133:265-79.

20. Taimela S, Kujala UM, Salminen JJ, Viljanen T. The prevalence of low back pain among children and adolescents: a nationwide, cohort-based questionnaire survey in Finland. Spine 1997;22:1132-6.

21. Balague F, Troussier B, Salminen JJ. Non-specific low back pain in children and adolescents: risk factors. Eur Spine $J$ 1999,8:429-38.

22. Andersson GBJ. The epidemiology of spinal disorders. In: Frymoyer JW, editor. The adult spine: principles and practice. Philadelphia: Lippincott-Raven; 1997;p.93-141.

23. Singleton MA, Rosen JI, Fisher DM. Pharmacokinetics of fentanyl in the elderly. $\mathrm{Br} J$ Anaesth 1988;60:619-22.

24. Richardson J, Bresland K. The management of postsurgical pain in the elderly population. Drugs Aging 1998;13:17-31.

25. Anderson JT, Haas AR, Percy R, Woods ST, Ahn UM, Ahn NU. Chronic opioid therapy after lumbar fusion surgery for degenerative disc disease in a workers' compensation setting. Spine 2015;40:1775-84. 